\title{
CRÍTICA DE ARTE E ANÁLISE CRÍTICA DO DISCURSO: INTERPRETAÇÕES SOBRE A PRODUÇÃO FOTOGRÁFICA DE ALAIR GOMES.
}

\footnotetext{
André Pitol é graduado em Artes Plásticas pela ECA-USP e mestrando no Programa de Pós-Graduação em Artes Visuais na mesma instituição, com pesquisa sobre a produção fotográfica de Alair Gomes publicada nos Estados Unidos nas décadas de 1970 e 1980.

E-mail: pitolpitolpitol@gmail.com
}

\section{Resumo}

Este artigo visa discutir as interpretações que a crítica de arte brasileira realizou, entre 1984 e 2006, sobre a produção fotográfica de Alair Gomes. Abordaremos as questões levantadas a partir da esfera da crítica de arte e o aporte teórico/ metodológico da Análise Crítica de Discurso (ACD).

Abstract

This paper aims to discuss the interpretations that Brazilian art criticism conducted between 1984 and 2006, about the photographic production of Alair Gomes. Address issues raised from the sphere of art criticism and theoretical approach / methodology of Critical Discourse Analysis (CDA).

\section{1) Introdução}

Este texto tem como questão principal a discussão sobre a produção fotográfica de Alair Gomes e as diferentes interpretações de críticos e pesquisadores de arte. Os textos críticos analisados aqui estendem-se desde meados da década de 1980 até a segunda metade dos anos 2000, especificamente as críticas de Roberto Pontual (1984), Walmyr Ayala (1984), Frederico Morais (1984), Tadeu Chiarelli (1999), João Luiz Vieira (2003; 2005), Wilton Garcia (2002; 2004) e Alexandre Santos (2006).

$\mathrm{O}$ debate proposto abrange alguns setores do campo artístico, especialmente a crítica de arte. Faremos uma apresentação contextualizada sobre alguns elementos que caracterizaram sua configuração a partir da segunda metade do século XX. Propomos uma comparação com os estudos da Análise Crítica do Discurso (ACD), a fim de compreender melhor as formas de transmissão de conhecimento propiciadas pelas esferas de recepção dos trabalhos artísticos e os interesses implicados nelas, principalmente na cena brasileira.

Não podemos deixar de enfatizar que a produção textual sobre os trabalhos de Alair Gomes insere a questão no imbricamento entre a arte e a sexualidade, assim como as transformações levadas a cabo por ela desde os anos 1970, aprofundando as reivindicações políticas das chamadas minorias sexuais ou, como aponta Michel Foucault (2006, p. 48), do "surgimento das sexualidades periféricas".

Porém, antes de adentrar ao texto, convém apresentar um sucinto relato sobre o artista em questão. Alair de Oliveira Gomes (1921-1992) desenvolveu sua produção fotográfica no Rio de Janeiro, desde o final dos anos 1960. Sua obra explora, entre outros temas, a presença do corpo das artes visuais, especificamente o corpo masculino em diversas situações: exercitando-se na praia de Ipanema ou nas ruas próximas à orla, ou simplesmente caminhando por esses locais.
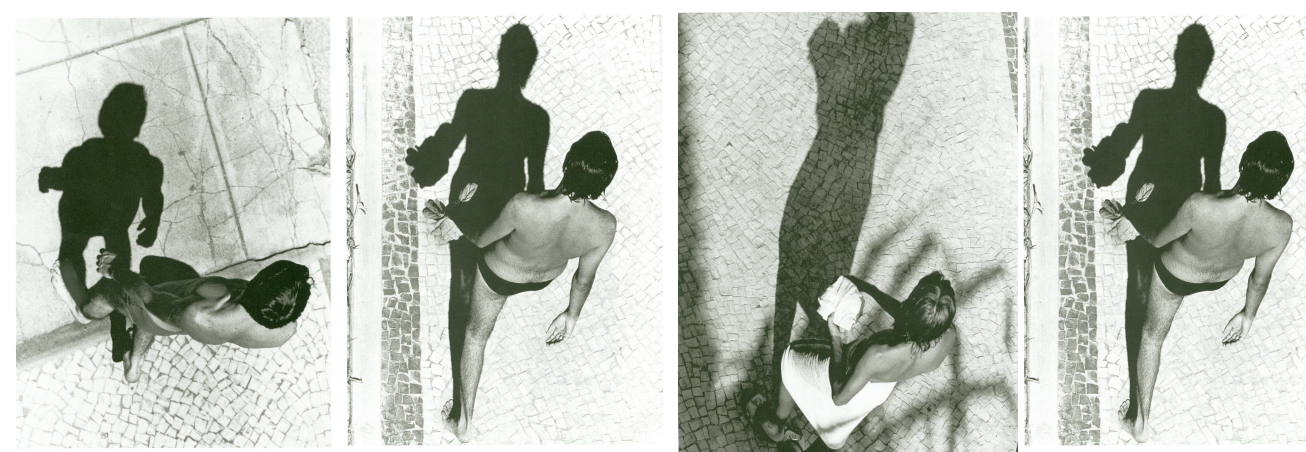

Fig. 1- 4. Alair Gomes. The Course of the Sun. c. 1977-1980. Fragmentos. 
A partir da tomada sequencial de fotografias de uma cena, Gomes rearranja o conjunto de imagens, no intuito de criar montagens ficcionais, resultando em séries que variam de trípticos até montagens com 30 ou mais imagens dispostas a criar uma narrativa. Pelo menos dois pontos são cruciais em sua produção. A primeira é a relação contígua estabelecida entre as fotografias, realizada ou pela disposição e montagem das imagens na sequência em que elas foram fotografadas - como em uma montagem fílmica - ou então pela combinação de partes de diferentes momentos das sessões de fotos, intercalando as imagens ou arranjando-as de modo aleatório. $\mathrm{O}$ segundo ponto significativo é o papel de destaque que a janela desempenha no processo de produção das fotografias. A distância física que Gomes toma do objeto fotografado é articulada pela proximidade proporcionada por lentes fotográficas, produzindo uma relação de distanciamento simbólico importante para a sua obra.

Alair Gomes realizou estes trabalhos de modo muito reservado e discreto. Um dos motivos possíveis para essa condição seria ter vivido e produzido sob a ditadura militar. Provavelmente sua temática fotográfica não o favorecia a exibi-la sem alarde. Gomes começou a apresentar suas imagens fora do país na segunda metade da década de 1970, especialmente nos Estados Unidos. Suas primeiras exposições no Brasil datam dos anos 1980, já no período de abertura política. Por isso mesmo, não chegou a constituir uma carreira artística no Brasil. A recepção de sua obra se deu na década de 1980 por um nicho de amigos e, só após sua morte, ela começou a ser exibida num cenário artístico mais amplo, participando de importantes mostras no cenário nacional e internacional.

\section{2) Análise Crítica do Discurso e Crítica de Arte}

Como foi dito, o objetivo deste estudo é discutir as alterações dos significados ocorridos na recepção das séries fotográficas de Alair Gomes por parte da crítica de arte. Mas, antes de nos debruçarmos nos textos da crítica, apresentaremos algumas questões metodológicas de auxílio às análises realizadas. Na pesquisa de trabalhos que estudaram as transformações de sentido (políticas, sociais, mas também de gênero e de sexualidade) de textos escritos, aproximamo-nos do campo da Análise Crítica do Discurso (ACD).

Optamos por utilizar seu instrumental teórico pela abordagem interdisciplinar que ela oferece no trabalho de análises de textos e de discursos que ultrapassam o nível gramatical, possibilitando a discussão a nível cultural. Esse campo de estudos possibilita também uma abordagem de análise textual que compreenda um corpus heterogêneo, questão que especificaremos a seguir.

Podemos situar o surgimento dos estudos sobre o Discurso, ou sobre os Discursos, na segunda metade do século XX, principalmente a partir dos anos 1960, período no qual novas propostas teóricas preocupadas com o funcionamento da linguagem em uso, com a introdução de "componentes pragmáticos e a dimensão social [que] começa a fazer parte do estudo da língua com o objetivo de combater a perspectiva estruturalista que vigorava" (Melo, 2009, p. 2). Ou seja, começa-se a perceber que "a linguagem, antes considerada um sistema interno e autônomo, tem funções externas que, não sendo autossuficiente, precisam ser analisadas a partir de seus usos" (Ramalho; Resende, 2006, p. 13). Assim, o estudo a que a Análise do Discurso se propõe não é "tão somente da língua, mas o que há por meio dela: relações de poder, institucionalização de identidades sociais, processos de inconsciência ideológica, enfim, diversas manifestações humanas" (Melo, 2009, p. 3).

Reconhecemos na figura de Norman Fairclough um importante interlocutor. O 
autor é considerado o expoente da Análise Crítica do Discurso - ACD. Desenvolvido e utilizado por ele desde meados da década de 1980 - a partir dos estudos da Linguística Crítica inglesa da década de 1970 e de referências da Escola de Frankfurt e das teorias neomarxistas de Gramsci (Melo, 2010) -, o termo consolidou-se como disciplina no início da década de 1990 (Ramalho; Resende, 2006).

Como coloca Fairclough, “por análise 'crítica' do discurso quer dizer análise do discurso que visa a explorar sistematicamente relações frequentemente opacas de causalidade e determinação entre (a) práticas discursivas, eventos e textos" (Fairclough, 2001 b, p. 35). A primeira questão a ser colocada como resultado da intervenção crítica na Análise do Discurso é a relação entre o discurso e o social. Fairclough entende que "produzir um discurso faz parte de processos mais amplos de produção da vida social, das relações sociais e das identidades sociais" (2001, p. 40).

Deste modo, o autor procura investigar "a mudança da linguagem como mudança sociocultural" (Melo, 2010, p. 96) e, desta forma, "levanta o véu da naturalização feita das relações de poder abusivas que se materializam discursivamente em várias esferas sociais" (Melo, 2010, p. 98).

Analiticamente, Fairclough desenvolve a relação descrita acima no que ele chama de Análise do Discurso orientada linguística e socialmente. Esse modelo é articulado por Fairclough a partir de três dimensões passíveis de serem analisadas - a perspectiva tridimensional do discurso: o texto, a prática discursiva e a prática social (2001a; 2001b). O texto é o objeto da análise estritamente, a dimensão textual da pesquisa; a prática social é o que o texto representa socialmente (2001a). A mediação entre os dois polos - texto e prática social - é feita pela prática discursiva, que "focaliza os processos de produção, distribuição e consumo textual" (2001a, p. 99), e são "variáveis entre os diferentes tipos de discurso, de acordo com os atores sociais envolvidos" (Ramalho; Resende, 2006, p. 28). Entendemos por prática discursiva toda atividade de divulgação, distribuição de informações ou posicionamentos críticos sobre arte que acarretará a tomada de posição daqueles que receberão as mensagens.

Um dos aspectos que Fairclough coloca como uma das partes possíveis de análise da prática discursiva é o conceito de interdiscursividade (2001b). Segundo o autor, ela "enfatiza a heterogeneidade normal dos textos que são constituídos por combinação de gêneros e discursos diversos" (Fairclough, 2001b, p. 37). Este conceito é ligado ao de intertextualidade, que estuda "a visão histórica dos textos como transformadores do passado - convenções existentes, ou textos anteriores - no presente" (Fairclough, 2001b, p. 37).

Transpondo as noções apresentadas acima para a esfera da crítica de arte, é possível perceber a diversidade de corpus com que se configura a crítica de arte. Especificamente, acerca do corpus de textos críticos sobre a produção fotográfica de Alair Gomes (análises pontuais de trabalhos ou textos comparativos), percebemos que esse conjunto compartilha elementos heterogêneos, conforme o local para onde foi escrito e publicado e as intenções dos autores. Estes aspectos articulando-se também à instabilidade de definição contemporânea do que seja a crítica de arte.

Depois da contextualização realizada, podemos aproximar a ACD com a crítica de arte. Cabe-nos o questionamento sobre a pretensão de utilizar procedimentos analíticos da ACD para compreender o discurso da crítica de arte. O trabalho aqui desenvolvido coloca-se numa posição especulativa sobre as condições de possibilidade de se realizar uma comparação entre os dois campos de estudo. Da mesma forma, tornase imprescindível não perdermos a oportunidade para discutir um aspecto importante da crítica de arte contemporânea - principalmente a articulação entre a arte e a sexualidade no trabalho fotográfico de Alair Gomes. Seria conveniente articular a constituição do 
campo da crítica de arte como um discurso que estabelece leituras interpretativas a partir da produção artística. Partindo do mesmo marco temporal utilizado no tópico sobre ACD - a década de 1960 -, apresentaremos algumas questões da crítica de arte no período, caracterizado por mudanças significativas nas relações da disciplina artística.

Segundo o argumento de Arthur Danto (2006), as décadas de 1960 e 1970 foram anos nos quais diversos artistas experimentaram tanto novos materiais para os trabalhos de arte, quanto novas formas de apresentação deles, como uma maneira de ressignificação de suas poéticas. $\mathrm{O}$ período pode ser entendido como um momento no qual as obras de arte não podiam ser determinadas por uma estrutura formal padronizada e no qual as estruturas narrativas mestras da história da arte tradicional baseados no critério de "imitação" - e da arte modernista desgastaram-se, deixando de desempenhar um papel onipresente na produção contemporânea.

Podemos relacionar o diagnóstico do autor também à nova configuração da crítica de arte no período. Peter Osborne (2010), ao discutir os impasses travados pela produção de arte conceitual no final da década de 1960 e começo dos anos 1970, afirma que, na referida época, diversos artistas evidenciavam os limites a que a crítica de arte havia chegado ao aproximar sua atividade artística com a atividade crítica. Isso se deu por "uma série de mudanças na relação entre atividade artística e crítica de arte que tiveram lugar na primeira metade dos sessenta" (Osborne, 2010, p. 82).

$\mathrm{O}$ autor acrescenta que tal situação era parte da crise pela qual passava a crítica modernista da arte, nos termos dos escritos de Clement Greenberg, e a nova relação estabelecida entre os trabalhos de arte e o observador (Osborne, 2010). Incluem-se aqui a nova configuração da arte pela introdução da fotografia, não mais como meio autônomo e separado de pinturas, esculturas ou outros suportes, mas discutido como obra de arte, forma artística (Osborne, 2007). A discussão de Osborne versa sobre um período de inflexão drástica. Contudo, nos desdobramentos surgidos desse vértice, criaram-se espaços para a apresentação de outras configurações possíveis, tanto da perspectiva do trabalho de arte, quando da perspectiva da crítica de arte.

Glória Ferreira (2006) aponta a década de 1960 como a época de decisivo deslocamento do debate artístico, na passagem de críticas vinculadas a discursos de tradição nacional, como os textos de Mário de Andrade, para o debate de uma linguagem não subordinada às tradições regionalista. A autora identifica esse deslocamento principalmente com a contribuição significativa dos textos de Mário Pedrosa, como no texto Do porco empalhado ou os critérios da crítica, de 1968. O crítico afirma que "a época contemporânea tem sido particularmente fértil em mudanças de critérios críticos, em mudanças de valores, em face das mudanças sucessivas de escolas, estilos, movimentos" (Pedrosa, 2007, p. 231). Assim, para Ferreira (2006), as reflexões de diversas ordens e contextos históricos sobre a crítica de arte evidenciam a permanente interrogação sobre seus critérios e as funções que pautam sua atividade.

Já no contexto das últimas décadas do século XX, Sônia Salzstein afirma que o período da década de 1980 marca uma alteração no lugar da crítica de arte, principalmente do espaço da produção acadêmica e intelectual para "vincular-se mais imediatamente às demandas profissionais, setorizadas, e corporativas, do universo das instituições contemporâneas da arte" (Salzstein, 2003, p. 88). Fernando Cocchiarale concorda e afirma que essa situação também deflagrou "uma crise na reflexão estética e na crítica de arte" (Cocchiarale, 2006, p. 377). Ele declara, porém, que a manifestação do campo da arte acerca da crise pode ser discutida de modo mais amplo. Ou seja, o autor não considera que essas mudanças impossibilitem ou tornem desnecessário o seu papel no debate artístico.

Basbaum (2001) aponta outros caminhos da crítica e da reflexão sobre arte no 
processo cultural brasileiro contemporâneo. O autor identifica uma relação difícil com as artes visuais, um processo que torna nítida a heterogeneidade do corpus da crítica de arte, como em textos escritos como apresentação de exposições ou para revistas especializadas que, para o autor, "carregam as marcas da reflexão sobre um segmento ou problema particular a determinada produção" (Basbaum, 2001, p. 13).

Identificamos na afirmação de Basbaum significativa similaridade com nosso tema. A organização e a análise de textos críticos das mais diferentes proveniências, publicados em suportes com objetivos bastante específicos. Percebemos com isso a diversidade do corpus que configura a crítica de arte sobre a produção fotográfica de Alair Gomes, aproximando a discussão aos conceitos de intertextualidade e interdiscursividade propostos por Fairclough (2001b). É a partir dessa perspectiva interdisciplinar que escolhemos analisar os textos críticos sobre o fotógrafo junto à Análise Crítica do Discurso.

Em resumo, percebemos que a crítica de arte, a despeito das significativas mudanças ocorridas em seu meio e dos novos rumos tomados, não foi relegada simplesmente ao segundo plano no campo artístico. Ela é uma esfera importante na recepção, divulgação, interpretação e discussão de trabalhos de arte. Em outras palavras, a crítica de arte, dentro da nova configuração que se encontra inserida, é ainda uma prática discursiva pertinente para o debate artístico, justamente porque as alterações percebidas no seu campo pertencem às alterações ocorridas na arte principalmente a partir dos anos 1960.

Passaremos agora às análises dos textos críticos sobre a produção fotográfica de Alair Gomes e as discussões que eles suscitaram, tanto nos aspectos artísticos, quanto nos aspectos argumentativos, na estruturação de enunciados que se destinam a informar o público leitor, resultando muitas vezes na institucionalização de identidades sociais (Melo, 2009) ou, como aponta Fairclough, nos "processos mais amplos de produção da vida social, das relações sociais e das identidades sociais" (2001, p. 40).

\section{3) Interpretações sobre a produção fotográfica de Alair Gomes}

O primeiro texto discutido é Imagem: Alma do corpo, corpo da alma, de Roberto Pontual, publicado no catálogo da exposição Corpo \& Alma: Fotografia Contemporânea no Brasil, apresentada em Paris em 1984 e no Rio de Janeiro em 1985. A exposição reuniu trabalhos de José Oiticica Filho, Alair Gomes, Mário Cravo Neto, Iole de Freitas, Vera Chaves Barcellos, Lygia Pape e Hugo Denizart.

Podemos ver esta exposição como uma resposta crítica de Pontual a uma série de mostras de arte brasileira apresentadas naqueles anos na França e tidas pelo autor como exposições que retrataram de modo documental os aspectos físicos e sociais do Brasil, mais do que "apresentar sua fotografia como meio autônomo de expressão" (Pontual, 1984, p. 7). O autor também diagnostica um ponto para ele é problemático: a "praga do exotismo que assola o olhar lançado de fora sobre a América Latina" (Pontual, 1984, p. 7), referindo-se a um amplo campo de imagens, expressões e julgamentos sobre a configuração sociocultural de países localizados fora do eixo europeu-estadunidense.

O título Corpo \& Alma foi dado para conotar o aumento significativo da presença do corpo em evidência no Brasil, que Pontual diz estar nos "jornais, nas revistas, nas telas, nos vídeos, no comércio e no pano de fundo geral” (1984, p. 8). Podemos incluir nesta sua descrição a presença do corpo nas artes visuais, não apenas como objeto de trabalhos artísticos, como também a ação do corpo na realização de trabalhos de arte, como nas performances, nos happenings e outros.

Pontual afirma que o teor conceitual da exposição encontra-se no "abismo que 
separa diferença de exotismo e o confronto que não cessa de dar-se, na fotografia, entre a imagem-documento e a criação com a imagem" (Pontual, 1984, p. 8). Com a intenção de atualizar o entendimento da fotografia produzida no Brasil para o público estrangeiro, Pontual redireciona a perspectiva de análise de alguns trabalhos fotográficos, a fim de armar diferenças no olhar redutor do estrangeiro "como antídoto contra o veneno do exotismo" (Pontual, 1984, p. 8).

Uma das maneiras usadas por Pontual para discutir a diferença brasileira na fotografia seria a relação complementar entre a fragmentação e a sequência. $O$ autor coloca que a relação entre os dois elementos acontece em diversos níveis, mas enfatiza o "duplo sentido da fragmentação e da recomposição simultâneas do corpo" (Pontual, 1984, p. 10) presentes nos procedimentos plásticos dos artistas. Pontual conclui, com isso, o motivo pelo qual nenhum dos fotógrafos da exposição Corpo \& Alma vêm de uma atividade estritamente fotográfica, mas artística. Ou seja, eles não se encontram na posição de fotógrafos que pretendem expor suas fotografias como arte, e sim artistas que realizam seus trabalhos por meio da utilização e manipulação de prática fotográfica, bem como situam suas produções na discussão do campo artístico.

Após as considerações gerais, Pontual passa à análise da produção fotográfica de cada um dos artistas escolhidos para a exposição Corpo \& Alma. Passaremos ao raciocínio do autor sobre os trabalhos de Alair Gomes.

Alair Gomes é colocado como o fotógrafo que magnifica a presença do corpo no universo do olhar. Pontual compara seus trabalhos com as fotografias científicas de elementos formais não-figurativos de José Oiticica Filho. Coloca ainda a obsessão de Gomes pelo mundo figurativo, ligando-a ao seu papel como crítico de arte (como aquele que procura conhecer e explicar as coisas do mundo) e de seus estudos sobre filosofia e natureza (entendida como sinônimo do fluxo da vida). A fotografia atuaria nesse mundo figurativo do artista como o processo de contenção deste fluxo da vida, de contenção do tempo presente ou, nas palavras de Pontual, "nas duas dimensões do termo conter: a de abarcar e a de reprimir" (Pontual, 1984, p. 11). Para ele, a contenção do fluxo vital de Gomes se deu primeiro na escrita dos diários filosóficos e eróticos, produzidos com interrupções em diversos momentos desde a juventude do fotógrafo - e passando posteriormente para a fotografia. A relação com o fluxo vital ou com a natureza é também citada pela escolha do objeto fotografado por Gomes: o corpo juvenil masculino.

O ato fotográfico é tido, para Pontual, como o contraste entre a imagem de esplendor do corpo "belo, perfeito e íntegro" e a ameaça do contexto específico de registro destas fotografias, realizadas na praia de maneira não-autorizada por parte do modelo. Esta particularidade garante uma dualidade entre naturalidade e pose por parte dos rapazes e a relação de entrega e furto das imagens por parte de Alair Gomes.

Recapitulando, o sentido de diferença utilizado por Roberto Pontual é colocado de forma ampla e ainda sem relações evidentes com uma discussão entre o corpo e a sexualidade, como se verá nas análises críticas posteriores sobre a produção de Gomes. Em nenhum momento do texto do autor as séries de rapazes na praia foram relacionadas com uma ação resultante de um condicionamento a priori homoerótico. A única aproximação possível do tema do corpo em Gomes é realizada por Pontual na introdução à análise da produção de Iole de Freitas. Pontual afirma que "se o corpo masculino toma inteiramente a fotografia de Alair Gomes e se tanto o homem quanto a mulher habitam o universo tenso e estático de Mário Cravo Neto [é] com Iole de Freitas [que] as trocas se fazem sempre através do corpo da mulher" (1984, p. 13). Ou seja, o cotejamento foi feito apenas como procedimento retórico para o trabalho de Iole de Freitas. 
Seria conveniente neste momento relacionar as reflexões de Pontual com alguns outros posicionamentos da cena artística do período. As primeiras participações de Alair Gomes em exposições no Brasil datam de 1978, com o trabalho Fotos do Carnaval de Rio, no Salão do Carnaval de Belo Horizonte, e em 1980, com uma exposição no Shopping Cassino Atlântico, Rio Janeiro, dentro do Programa As artes no Shopping.

Porém, 1984 foi o ano no qual os trabalhos de Alair Gomes foram apresentados em diversas mostras. Além da exposição realizada por Roberto Pontual em Paris, Alair Gomes participou da I Quadrienal de Fotografia do Museu de Arte Moderna de São Paulo e, no Rio de Janeiro, da exposição individual Alair Gomes: fotografia sequencial, na Galeria de Arte do Centro Cultural Cândido Mendes.

Propomos discutir brevemente a recepção obtida pela exposição Alair Gomes: fotografia sequencial. É possível, desta forma, acompanhar seu debate minimamente possível nos jornais de grande circulação do período.

No texto do crítico de arte Walmyr Ayala, este afirma que a fotografia de Gomes tem um componente estrutural. $\mathrm{O}$ autor coloca que, sem deixar de considerar o referente das imagens, ou seja, o erotismo do "corpo jovem, esportivo, seminu, contemporâneo e balneário" (Ayala, 26 e 27/08/1984, s/p), as séries de Gomes, os trabalhos como Beach Triptycs, Sonatinas, four feet e Frisos concentram-se em um tipo de contenção formal. Além deste termo, o autor utiliza outros para sublinhar este aspecto formal, construtivo do trabalho, por exemplo, "o corpo como vértebra da composição, enriquecida pelos detalhes da sombra, dos instrumentos [de ginástica] e, até mesmo da textura da areia", onde "prevalece o desenho" (Ayala, 26 e 27/08/1984, s/p).

Já na breve nota de Frederico Morais, o crítico relaciona os elementos sequenciais da produção fotográfica de Gomes ao modelo de montagem cinematográfica utilizado por Sergei Eisenstein (Morais, 19/08/1984, p. 3). Acrescenta também que, no lugar de privilegiar a nitidez da imagem, utiliza sua ausência a fim de ressaltar os valores plásticos delas, encarando-as como esboços fotográficos.

Resumindo, as colocações de Ayala e Morais evidenciam os aspectos de montagem das imagens fotográficas em sequência, de forma que o conjunto delas crie resultados plásticos que supostamente se aproxime de elementos do cinema, cujo movimento é gerado pela passagem de imagens fixas em determinada rotação no tempo. Do mesmo modo que Pontual, a concepção de fotografia de ambos os críticos não ressalta exclusivamente o referente da imagem no lugar de sua manipulação e distribuição espacial do trabalho.

$$
* * *
$$

É com diagnóstico diferente das colocações de Pontual, Ayala e Morais que o professor e pesquisador Tadeu Chiarelli inicia um texto sobre a fotografia brasileira contemporânea: "A fotografia brasileira nos anos 90 atingiu sua 'maioridade' internacional" (Chiarelli, 1999, p. 142). A opção declarada do autor é a realização de um mapeamento da situação fotográfica brasileira naquele momento.

Dentre os artistas que passaram por esta revisão nos escritos sobre arte no Brasil, segundo Chiarelli, estaria Alair Gomes, "produção fotográfica de um artista até poucos anos completamente desconhecido de um público mais amplo [...], sua obra construída a partir, sobretudo, de um voyeurismo de cunho homoerótico, ainda aguarda - mesmo no Brasil - uma avaliação mais profunda" (Chiarelli, 1999, p. 142). Percebemos já uma alteração importante na recepção da fotografia de Alair Gomes. O autor a vê a partir do voyeurismo e não mais pela perspectiva na montagem sequencial das imagens, como os críticos analisados no início da análise.

A parte final do texto é dedicada à breve apresentação de uma "jovem produção contemporânea [cujo] centro de interesse vem sendo a exploração/ampliação do 
universo homoerótico" (Chiarelli, 1999, p. 149). O autor coloca a obra de Gomes como a primeira a tratar do tema no Brasil e, a partir dele, posiciona a atuação da produção contemporânea (sem, contudo, afirmar uma relação direta de influência entre a primeira produção e as do novo contexto). Como partícipes da nova geração, Chiarelli indica Hudinilson Jr., artista cujo trabalho resulta da apropriação de seu próprio corpo, reproduzindo-o em cima de uma máquina copiadora, dentre diversos outros trabalhos e, sobre produções mais recentemente, comenta os trabalhos de Eli Sudbrack e Hélio Melo.

Sem estender a questão, apresentamos sucintamente uma questão principal acerca do referido texto. $\mathrm{O}$ trabalho de Melo - um ensaio fotográfico tirado nas ruas de São Paulo com imagens do tórax masculino de diversos homens - é tido por Chiarelli como "um dos mais caros fetiches homoeróticos" (Chiarelli, 1999, p. 150). O autor aponta que uma das questões do trabalho aparenta ser "a desestabilização do universo gay pela dessublimação desse fetiche que, nesses tempos de Aids - e através apenas de fotografias - parece estar se tornando um dos únicos objetos de prazer permitido para muita gente" (Chiarelli, 1999, p. 150).

Essa informação abre espaço para uma consideração entre os campos da arte e da sexualidade, especificamente em alguns momentos históricos nos quais essa junção torna-se significativa. Atentaremos em um ponto que consideramos importante na leitura de Chiarelli sobre o trabalho de Gomes: as leituras possíveis entre o homoerotismo - no sentido de um aspecto da questão gay - e a AIDS.

Segundo o argumento de Facchini e Simões (2009, p. 51) "a partir da década de 1980, o ativismo pela homossexualidade passaria a enfrentar outro [...] desafio: a eclosão da epidemia do HIV-Aids". Isso porque, na época, os casos que alertaram para a emergência da nova enfermidade foram diagnosticados nas mortes de diversos homens homossexuais nos Estados Unidos. No Brasil, os primeiros casos diagnosticados deram-se em 1982, apenas um ano após o conhecimento dos casos norteamericanos. Nesse período, a relação entre a homossexualidade e a Aids era insistente nos diversos setores da sociedade (Facchini; Simões, 2009).

Mas, como os autores também apontam, "as respostas à epidemia da HIV-Aids resultaram também em experiências inovadoras no ativismo pela homossexualidade em muitos lugares" (Facchini; Simões, 2009, p. 52) e, ainda na década de 1980 e durante a década seguinte, a formação de várias associações, grupos organizados ou iniciativas individuais foram, pouco a pouco, modificando a relação estabelecida acima, a fim de construir um novo campo de discussão sobre a homossexualidade, esclarecendo à sociedade a relação não causal da homossexualidade e da Aids como doença.

Retornando ao texto de Chiarelli, verificamos que, tanto o trabalho de Hélio Melo quanto o próprio texto são de 1997, ou seja, pertencem à segunda metade da década de 1990, época posterior a todo o debate de equívoco interpretativo sobre as questão entre homossexualidade e Aids.

Podemos ainda supor que a relação feita por Chiarelli entre homossexualidade e Aids foi dirigida especificamente à produção de Hélio Melo e não sobre a de Alair Gomes. Porém, como discutido no espaço dedicado à Análise Crítica do Discurso, a linguagem tem funções externas a seu próprio sistema e, por isso mesmo, precisa ser analisada a partir de seus usos (Ramalho; Resende, 2006). Compreendemos que um texto não pode ser entendido com base em frases separadas de seu entorno, mas sim discutidas no conjunto das sentenças que geram sentido. Assim, concluímos que, ao colocar os trabalhos dos dois artistas no encadeamento de argumentos no mesmo parágrafo, o autor sugere este tipo de relação.

Podemos ainda retomar a noção de interdiscursividade, proposta por Fairclough, 
posta como "a heterogeneidade normal dos textos que são constituídos por combinação de gêneros e discursos diversos" (Fairclough, 2001b, p. 37), nos quais qualquer discurso construído afeta tanto o plano do texto, da prática discursiva, quanto da prática social, já que, para o autor, o texto é orientado linguística e socialmente. Sendo assim, a organização textual dos discursos não é aleatória, uma vez que ela depende de determinações e restrições discursivas e é constituída de escolhas.

Em resumo, procuramos enfatizar aqui um esforço de "desvincular a homossexualidade da conotação de patologia e reconstituí-la como formas possíveis, legítimas e vitoriosas de ser e viver" (Facchini; Simões, 2009, p. 53). Esta reconstituição passa também pelas formas de representação da sexualidade, incluindo também os regimes visuais de representação. Nosso esforço foi o de demonstrar os limites a que pode chegar esta questão. Enfim, mesmo que nesse momento tenhamos nos afastado das proposições estritas da análise da crítica de arte, acreditamos que esse esforço de escrita foi gerado pelos argumentos apresentados pela crítica de arte.

Avançando nos textos críticos, apresentaremos agora mais uma etapa deste trabalho sobre a construção discursiva acerca da produção fotográfica de Alair Gomes.

A pesquisa de João Luiz Vieira resultou principalmente nos textos: "O corpo do voyeur: Alair Gomes e Djalma Batista" (2001; 2003) e "Alair Gomes, Djalma Batista e Pedro Almodóvar: o circuito do desejo" (2005; 2011).

Vieira propõe uma pesquisa que reúna, a partir da fotografia e do cinema, o corpo humano como discurso, "ênfase no corpo masculino através do trabalho de dois artistas brasileiros, pioneiros na articulação de uma linguagem do desejo homoerótico" (Vieira, 2003, p. 69). Os artistas são Alair Gomes e o cineasta Djalma Limongi Batista. Para Vieira, os pontos de contato entre ambos são, além do desejo da imagem, a forma de escrita teórica e pessoal elaborada em cada caso. A relação entre Alair Gomes e o conceito de escrita pessoal, proposto por Vieira a partir do trabalho de Denílson Lopes, será o mote principal da tese de Alexandre Santos (2006), analisada posteriormente neste trabalho. Percebemos, já no começo, que o autor analisa a produção do fotógrafo a partir do argumento do desejo homoerótico.

Depois de passar por uma sucinta reflexão teórica sobre os textos fundadores da teoria cinematográfica contemporânea de base psicanalítica e pós-estruturalista dos anos 1970, Vieira chega à análise de Alair Gomes. A partir de um breve relato biográfico da vida do fotógrafo, Vieira aponta a década de 1970 como o momento no qual o fotógrafo dedica-se à sua obra (Vieira, 2003). Só então ele aponta a organização sequencial das séries fotográficas, comparando-as ao campo musical, para logo em seguida apresentar a tensão, reconhecida pelo próprio fotógrafo, de que suas fotografias organizavam-se em "uma espécie de co-existência conflitante" (Vieira, 2003, p. 74) entre o erótico clássico e o pornográfico, ou também o aspecto do voyeur, da "tensão entre intimidade e distância" (Vieira, 2003, p. 76-77).

Desta forma, Vieira destaca a produção de Alair Gomes como "um caso singular na tradição erótica homossexual" (Vieira, 2005, p. 97), afirmando que, "como nas fotos de Alair Gomes, o espectador é apanhado primeiro pelo erotismo, independente dos conteúdos formais e de interesse intelectual" (Vieira, 2003, p. 78; 2005, p. 101). Percebemos aqui claramente uma sobreposição da análise dos trabalhos fotográficos de Gomes - e os elementos implicados neles - para uma atitude que privilegia o referente fotográfico - corpos fotografados na praia ou nus - como o mote para ilustrar o que seria um artista homoerótico.

Já a pesquisa de Wilton Garcia - a tese Imagem \& Homoerotismo: a sexualidade no discurso da arte contemporânea (2002), publicada em livro (2004) - sobre as 
relações entre imagem e homoerotismo, inclui a produção fotográfica de Alair Gomes entre seus objetos de estudos, ou seja, nas produções artísticas contemporâneas que tratem de traços homoeróticos, no processo que o autor denominou homoarte ou arte homoerótica, ou ainda estética gay (Garcia, 2002). Seu objetivo é o de "potencializar as dimensões ética, estética e política [para] a construção do conceito de homoarte, inserido no âmbito da cultura brasileira" (Garcia, 2004, p. 53).

As análises sobre Gomes (Garcia, 2004) estabelecem primeiramente consonância com os argumentos de Chiarelli (1999) sobre a imagem de Alair Gomes junto ao processo de revisão histórica da fotografia brasileira no século XX, reproduzindo a noção colocada pelo autor de uma produção fotográfica composta "a partir do voyeurismo de forte cunho homoerótico". Inclui também o argumento de João Luiz Vieira (2003) sobre a noção de corpo do voyeur, "na busca do artista de um corpo como discurso poético" (Garcia, 2002, p. 135).

Mas, apesar das referências retiradas de Vieira (2003), Garcia desloca a questão do voyeur e dilui o argumento em vários parágrafos que pretendem colocar a produção fotográfica, ou ainda o artista Alair Gomes, numa "interpelação entre arte e erotismo [articulando] o trabalho deste artista para a expressão do desejo homoerótico, em que essa coexistência conflitiva expõe um erotismo aberto [...] do corpo masculino" (Garcia, 2002, p. 135-136). Notamos que o autor parte ainda do argumento de Vieira, que coloca a fotografia de Gomes como "uma espécie de coexistência conflitante" (Vieira, 2003, p. 74; 2005, p. 96). Garcia objetiva a colocação de Gomes a partir de um "ponto de vista de uma crítica sobre a discursividade visual; sobretudo no âmbito de uma erótica que solicita a revisão do pensamento contemporâneo" (Garcia, 2002, p. 137).

Recapitulando, nas colocações de Garcia, percebemos que sua proposta inverte o argumento no qual a fotografia de Gomes teria relação com a contenção do fluxo vital em uma série de relações compositivas e sequenciais (como já analisado nos tópicos anteriores), afirmando com isso o vínculo, para o autor, da produção do artista com o que denomina homoarte.

Em resumo, o que podemos perceber aqui é uma inversão na leitura sobre a produção fotográfica de Alair Gomes. Vieira (2003) afirma que as imagens de Gomes devem ser apanhadas pelo espectador "primeiro pelo erotismo, independente dos conteúdos formais e de interesse intelectual" (2003, p. 78), ou seja, renega os aspectos formais, constitutivos de um trabalho de arte, para segundo plano em suas considerações. Já para Garcia (2002), a perspectiva para a análise dos trabalhos de Gomes está articulada à "uma erótica que solicita a (re)visão do pensamento contemporâneo" (Garcia, 2002, p. 137), também insistindo na proposta de que as análises sobre a obra do fotógrafo devem partir do consenso de que se trata de um trabalho a priori erótico.

Finalizando as análises sobre as leituras do trabalho de Alair Gomes, analisaremos a contribuição de Alexandre Santos (2006). Como o autor aponta, seu interesse pela produção de Alair Gomes deu-se pela leitura do texto escrito por Tadeu Chiarelli em 1997, "Fotografia no Brasil: Anos 90" (Santos, 2006, p. 1). Enfatizamos com isso o aspecto de difusão da crítica de arte e os resultados de sua distribuição, que reportamos à noção do funcionamento discursivo discutido por Fairclough (2001a), segundo a qual está a circulação do texto, ou seja, evidenciamos aqui de que modo o trabalho de Santos é tributário dos discursos formulados anteriormente, em particular a sugestão de Chiarelli (1999).

Santos introduz a análise sobre os trabalhos de Alair Gomes a partir de uma pesquisa preliminar sobre artistas que trataram da questão da sexualidade, atentando 
justamente para os que fizeram uso da fotografia ou, como coloca o autor: a "construção histórica deste olhar comprometido e, portanto, confessional sobre o masculino" (Santos, 2006). Para o autor, seu principal objeto foi uma produção centrada na representação do desejo homoerótico como aspecto inteiramente dominado por motivações de ordem biográfica (Santos, 2006).

O autor divide os trabalhos de Gomes em dois blocos de análises, nos capítulos intitulados "A poética do perto: a fotografia consentida" (Santos, 2006, p. 291-323) e "Poética do longe: a fotografia roubada" (Santos, 2006, p. 324-346). Neste texto, focaremos na argumentação do autor a respeito do segundo bloco, que é quase exclusivamente dedicada à reflexão dá série Symphony of Erotic Icons 1966-1977.

Santos estabelece uma articulação simbólica entre a câmera fotográfica que Alair Gomes valia-se para persuadir os rapazes e a concordância dos possíveis modelos para posar no estúdio do seu apartamento (Santos, 2006). O autor aborda demoradamente a série descrita acima, elaborando o argumento de que:

a máquina fotográfica era o phallus ativo que seduzia os modelos passivos, convencendo-os a posarem nus [...]. Porém, uma vez cumprido o ritual, percebe-se, entretanto, que há uma inversão desse suposto poder de sedução masculinizante do qual se investe Alair em sua estratégia inicial de aproximação. O fotógrafo desterritorializa seu lugar ativo [...] para assumir o lugar passivo do adorador dos corpos impressos no signo (Santos, 2006, p. 297)

Percebemos aqui a relação direta que o autor identifica entre a produção do fotógrafo e o erotismo e, especificamente, um tipo de análise investida de uma dicotomia entre o ativo e o passivo e a aplicação desta dicotomia na relação entre a produção fotográfica (a câmera fotográfica) e a biografia do fotógrafo (seus desejos). Daremos atenção tanto às elaborações propostas por Santos (2006), quanto procuraremos evidenciar seus limites. No caso, os limites que uma leitura baseada na divisão binária entre masculino e feminino estabelece para a consideração de um trabalho artístico que trate, segundo a própria crítica de arte, de aspectos do homoerotismo e da homossexualidade masculina, levando-nos às considerações discutidas por Foucault (2006) com a noção de "dispositivo da sexualidade", ou seja, um aumento e aprofundamento das questões ligadas a sexualidade, produtora de uma quantidade significativa de espaços de conhecimento onde o sexo foi colocado em discussão, viabilizando o "surgimento das sexualidades periféricas".

Sobre o lugar das sexualidades periféricas, Gayle Rubin (1979) propõe o conceito de sistema sexo/gênero, entendido como arranjos pelos quais uma sociedade transforma a sexualidade biológica em produtos da atividade humana. O sistema desdobra-se basicamente em dois princípios: o pressuposto da heterossexualidade e a criação do gênero. Para Rubin (1979) esta é a instituição de um tabu contra a uniformidade de homens e mulheres e contra os arranjos sexuais que fujam ao par homem e mulher, configurando uma assimetria entre ambos.

Embora o texto de Rubin faça referência às sexualidades de modo geral, seu foco de atenção e análise é a cena norte-americana. A respeito da situação brasileira, o antropólogo Edward MacRae afirma que "em se tratando de papéis sexuais, a sociedade tem dividido os indivíduos em dois tipos: o ativo (homem), e o passivo (mulher)" (MacRae, 1990, p. 51). Richard Parker acrescenta que "a questão de gênero tem definido, tradicionalmente, a interpretação brasileira [situada] no contexto de uma ordem social profundamente patriarcal, [na qual] os conceitos de macho e fêmea, de masculinidade e feminilidade forneceram as fundações sobre as quais o mundo de significações sexuais foi construído no Brasil” (Parker, 1991, p. 14-15). 
Percebemos, a partir dos argumentos acima, que as discussões sobre a sexualidade baseadas em análises que privilegiam categorias binárias - masculino e feminino - apresentam certa instabilidade, mas que, a despeito disso, permanecem. Parker afirma que "as interpretações de masculino e feminino da sociedade patriarcal ainda têm forças no pensamento contemporâneo brasileiro" (Parker, 1991, p. 63), de modo que ela tem "servido tradicionalmente como o princípio organizador para um mundo mais amplo de classificação sexual na vida brasileira atual” (Parker, 1991 p. 70).

Relacionando a citação acima e trazendo a discussão de volta a Santos (2006), percebemos a relação direta entre as oposições de ativo/passivo e masculino/feminino. Assim, mais elementos reforçam a suposição de que, ao invés de uma atualização das leituras sobre arte e sexualidade a partir das análises sobre a produção fotográfica de Alair Gomes - especialmente aqui as análises críticas de Alexandre Santos (2006) sobre a série Symphony of Erotic Icons -, a utilização de descrições binárias entre "atividade" e "passividade" pertencem, na verdade, há um modelo de entendimento das relações sociais arraigadas na sociedade brasileira vigente há bastante tempo, como aponta Parker (1991), mas ainda contemporâneo. Reforçamos, assim, que o exame crítico das categorias e identidades sexuais articulados às análises de trabalhos artísticos configurase como exercício de compreensão dos processos sociais, culturais e políticos evidentes em nossa atual sociedade.

Como alternativa à questão apresentada, Rubin (1979) demonstra a relevância do conceito de sexo e a possibilidade de desenvolvimento de estudos sobre a sexualidade para além da hierarquia dos corpos, de homens e mulheres. Esse esforço é também utilizado por Peter Fry (1981), que analisa representações que digam respeito à sexualidade privilegiando a retórica envolvida no assunto.

No caso de Santos (2006), essa retórica é formulada nas interpretações sobre a produção fotográfica de Gomes na oposição ativo/ passivo. É possível comparar o raciocínio de Santos (2006) acima apresentado ao modelo de "homens e bichas", desenvolvido por Fry (1981, p. 90-93), no qual o autor considera os papéis de "ativos" e "passivos" como assimétricos, classificando seus participantes a partir de uma hierarquia de gênero. Percebemos que, para Santos (2006), a negociação entre Alair Gomes e os modelos para a série fotográfica Symphony of Erotic Icons se dariam nesses termos.

$\mathrm{Na}$ tentativa de contrapor o modelo assimétrico descrito acima, Fry (1981) discute o surgimento de uma nova maneira de considerar a representação sexual: a figura do entendido. Essa nova forma de representação produziu-se, no caso brasileiro, em um contexto sócio-político específico, a saber: as classes médias de centros urbanos como, no caso de Alair Gomes, o Rio de Janeiro, na passagem dos anos 1960 para a década seguinte, período que coincide com o desenvolvimento inicial da produção fotográfica de Alair Gomes.

A identidade do indivíduo que compartilha dessa categoria é definido como um personagem que tem certa liberdade no que diz respeito ao seu papel de gênero e à sua "atividade" ou "passividade" (Fry, 1981), não sendo, por isso, obrigado a ser considerado sob tais pressupostos analíticos. Esse modelo de classificação pode ainda ser descrito da seguinte forma: "o modelo 'igualitário-moderno', que distinguia 'homossexuais' ('entendidos' ou 'gays') e 'heterossexuais' a partir de concepções de orientação do desejo sexual” (Simões, 2008, p. 537).

Retomando Santos (2006), acreditamos necessária uma atualização das análises sobre a produção fotográfica de Alair Gomes, não nos termos da assimetria de gênero, mas articular uma análise crítica sobre sua obra por meio de noções como as de Rubin (1999) e de Fry (1981). Dessa forma, construímos também uma possibilidade 
interpretativa sobre as formas de representações artísticas e analíticas para as relações entre arte e sexualidade.

Em resumo, concluímos que Alexandre Santos (2006) propõe uma discussão do trabalho fotográfico de Alair Gomes nos moldes de discussão atualizada de sexualidade e de homoerotismo, levando a cabo a sugestão de Chiarelli (1999), aprofundando o argumento de que a questão principal do trabalho de Gomes é a "representação do desejo homoerótico como aspecto inteiramente dominado por motivações de ordem biográfica" (Santos, 2006, p. 3). Os resultados de tais investigações, contudo, permaneceram nos procedimentos analíticos advindos do sistema hierárquico de gênero - a oposição ativo/passivo - sistema cujas relações assimétricas pressupõem ainda uma sociedade formada na desigualdade de gênero e na dominação do poder masculino sobre outras formas de representação de identidades sociais e de práticas artísticas.

\section{4) Conclusão}

Recapitulando as principais etapas de análise aqui apresentadas, no começo verificamos que os textos críticos privilegiaram nos trabalhos do fotógrafo elementos que problematizassem os valores estritamente documentais da fotografia, a partir da tomada sequencial de fotografias (Pontual, 1984), na consideração dos aspectos compositivos gráficos da imagem impressa (Ayala, 1984) e dos aspectos de organização narrativa do conjunto, assemelhando-o ao modelo de montagem cinematográfica (Morais, 1984). Depois, passamos às considerações de trabalhos que sugeriam uma discussão das séries de Gomes a partir de uma análise sobre o "voyeurismo de cunho homoerótico" (Chiarelli, 1999).

O enfoque que partia do pressuposto homoerótico da produção fotográfica de Alair Gomes foi alterando-se paulatinamente, com a intervenção e contribuição de vários críticos. Em um caso, essa mudança deu-se na análise dos trabalhos do fotógrafo pela articulação de uma linguagem do desejo homoerótico, independente dos conteúdos formais (Vieira, 2003; 2005). Em outro caso, vemos a tentativa de relacionar a produção fotográfica de Gomes para a revisão do discurso visual pelo foco da homoarte (Garcia, 2002; 2004).

Percebemos também como textos críticos que colocam o desejo homoerótico como questão primordial da fotografia de Gomes, relacionando-a às motivações de ordem biográfica do fotógrafo, ao voyeurismo e ao fetichismo fotográfico (Santos, 2006) evidenciam em suas análises modos de organização das identidades sociais assimétricas, que fundamentam as representações sexuais em categorias binárias e opostas, como as noções de atividade/passividade.

No que diz respeito à utilização da Análise Crítica do Discurso, verificamos que seu aporte teórico e metodológico foi de grande importância para as análises realizadas, principalmente nas relações propostas junto ao discurso da crítica de arte. Enfatizamos o conceito de prática discursiva, que comporta os processos de produção, distribuição e consumo de textos (Fairclough, 2001a), incluem ainda as práticas semióticas como as da fotografia (Fairclough, 2001b). Estas podem ser articuladas às noções de interdiscursividade e intertextualidade - à heterogeneidade dos discursos encontrados nos textos, como também as conexões que textos do passado fazem com o presente.

Este aporte têm significativa similaridade com a nova configuração da crítica de arte (Osborne, 2010), como a heterogeneidade do corpus da crítica de arte em diversos suportes (Basbaum, 2001), muitas vezes vinculadas à demandas de instituições contemporâneas da arte (Salzstein, 2003), mas ainda como espaço de discussão da produção artística (Cocchiarale, 2006). O estudo de textos e eventos em diversas práticas sociais descreve, interpreta e posiciona a linguagem dentro de um contexto 
sócio histórico (Magalhães, 2005), reforçando as transformações da linguagem como mudanças socioculturais, bem como no estabelecimento de representações de identidades sociais historicamente discriminadas (Melo, 2010).

Com relação às contribuições de Foucault (2006), chamamos a atenção para o que o autor denominou "dispositivo da sexualidade" ou "sexualidades periféricas", ou seja, um aumento e aprofundamento das questões ligadas a sexualidade e cuja dispersão configurou uma quantidade bastante significativa de espaços de conhecimento, colocando as sexualidades em discussão. Utilizamos também o conceito de sistema sexo/gênero (Rubin, 1979), entendido como arranjos pelos quais uma sociedade transforma a sexualidade biológica em produtos da atividade humana, dentre eles, as formas e os regimes de representação artística. Com isso, a autora demonstra a possibilidade de desenvolvimento de estudos sobre a sexualidade que ultrapassem a hierarquia dos corpos (Rubin, 1999).

Concluímos este texto conscientes de ter realizado uma tentativa possível de relações estabelecidas entre arte e sexualidade e a presença do corpo na fotografia de Alair Gomes, ou seja, na compreensão de trabalhos artísticos que se articulam ao exame crítico de categorias e identidades sociais da sexualidade, configurando processos culturais e políticos em nossa sociedade.

Referências Bibliográficas.

AYALA, Walmyr. "Artes Plásticas/ Fotografia/ Sonatinas e frisos". Jornal do Commercio, 26 e 27/08/1984, s/p.

BASBAUM, Ricardo (org.). Arte Contemporânea Brasileira: Texturas, dicções, ficções, estratégias. Rio de Janeiro: Rios Ambiciosos, 2001.

CHIARELLI, Tadeu. "Fotografia no Brasil anos 90". In: Arte Internacional Brasileira. São Paulo: Lemos Editorial, [1997] 1999, pp.141-150.

COCHIARALE, Fernando. "Crítica: a palavra em crise". In: FERREIRA, Glória (org.) Crítica de Arte no Brasil: tendências contemporâneas. Rio de Janeiro: Funarte, 2006, pp. 377-381.

DANTO, Arthur C. Após o Fim da Arte: A Arte Contemporânea e os Limites da História, trad. Saulo Krieger. São Paulo: EDUSP/ Odysseus Editora, 2006.

FACCHINI, Regina; SIMÕES, Júlio Assis. Na trilha do arco-íris: Do movimento homossexual ao GLBT. São Paulo: Editora Fundação Perseu Abramo, 2009. Coleção História do Povo Brasileiro.

FAIRCLOUGH, Norman. Discurso e mudança social. Coordenação da tradução: Izabel Magalhães. Brasília: Editora Universidade de Brasília, 2001a.

"A Análise Crítica do Discurso e a Mercantilização do Discurso Público: as Universidades". IN: MAGALHÃES, Célia Maria. Reflexões sobre a Análise Crítica do Discurso. Trad. Célia M. Magalhães. Belo Horizonte: Faculdade de Letras, UFMG, 2001b, pp. 31-81

FERREIRA, Glória (Org.). Crítica de Arte no Brasil: Temáticas Contemporâneas. Rio de Janeiro: Funarte, 2006.

FOUCAULT, Michel. História da Sexualidade: a vontade de saber, trad. Maria Thereza da Costa Albuquerque e J. A. Guilhon Albuquerque v. 1, $17^{\circ}$ ed. São Paulo: Graal, 2006.

FRY, Peter. Pra Inglês Ver: identidade e política na cultura brasileira. Rio de Janeiro: Zahar Editores, 1981.

GARCIA, Wilton. Imagem \& Homoerotismo: a sexualidade no discurso da arte contemporânea. 2002. 276f. Doutorado (Tese em Ciências da Comunicação) Universidade de São Paulo, 2002. 
. “Alair Gomes e a fotografia". In: Homoerotismo \& Imagem no Brasil. São Paulo: Wilton Garcia Editora, 2004.

MAGALHÃES, Izabel. "Introdução: A Análise de Discurso Crítica". Revista D.E.L.T.A, v. 21, Especial Análise Crítica do Discurso, 2005, pp.1-9.

MCRAE, Edward. A Construção da Igualdade: Identidade Sexual e Política no Brasil da "Abertura". Campinas, Editora da Unicamp, 1990.

MELO, Iran Ferreira de. "Análise do Discurso e Análise Crítica do Discurso: desdobramentos e intersecções". Revista Letra Magna: Revista electronica 05 n.11 $2^{\circ}$ semestre de 2009.

Análise Crítica do Discurso: um estudo sobre a representação de LGBT em jornais de Pernambuco. Recife: Ed. Universitária da UFPE, 2010.

MORAIS, Frederico. "Fotografia: o corpo como tema em Alair". O Globo, Segundo Caderno, 19/08/1984, p. 3.

OSBORNE, Peter. "La fotografia em um campo de expansión: unidad distributive y forma dominante". In: GREEN, David (Ed.) Que há sido de la fotografia? Colección FotoGGrafía. Barcelona: Gustavo Gili, 2007, pp. 66-76.

. El arte más allá de la Estética: Ensayos filosóficos sobre el arte contemporáneo. Murcia, Spain: CENDEAC, 2010.

PEDROSA, Mário. "Do porco empalhado ou os critérios da crítica". In: AMARAL, Aracy (Org.) Mundo, Homem, Arte em Crise. São Paulo: Ed. Perspectiva, 2007, pp. 231-236.

PONTUAL, Roberto. "Imagem: alma do corpo, corpo da alma". In: Fotografia contemporânea no Brasil/ Photographie contemporaine au Brésil: Corpo \& Alma. Rio de Janeiro: FUNARTE/Infoto, 1984. Catálogo de exposição.

RAMALHO, Viviane; RESENDE, Viviane de Melo. Análise de Discurso Crítica. São Paulo: Ed. Contexto, 2006.

RUBIN, Gayle. "O tráfico de mulheres: notas sobre a "Economia Política" do sexo". [1974] $1979 . \quad$ Disponível em: $<$ http://disciplinas.stoa.usp.br/mod/resource/view.php?id=6577>, último acesso em $11 / 08 / 2013$.

. "Thinking Sex: notes for a radical theory of the politics of sexuality". [1984]

IN: AGLETTON, Peter; PARKER, Richard (Ed.). Culture, Society and Sexuality: a reader. London: UCL Press, 1999, pp. 143-178.

SALZSTEIN, Sônia. “Transformações na esfera da crítica”. ARS, São Paulo, v. 1, p.8389, 2003.

SANTOS, Alexandre. A fotografia como escrita pessoal: Alair Gomes e a melancolia do corpo-outro. 2006. 399f. Doutorado (Tese em Artes Visuais) Universidade Federal do Rio Grande do Sul, 2006.

VIEIRA, João Luiz. "O corpo do voyeur: Alair Gomes e Djalma Batista”. In: NOJOSA, Urbano; GARCIA, Wilton. Comunicação \& Tecnologia. Nojosa, 2003.

"Alair Gomes, Djalma Batista e Pedro Almodóvar: o circuito do desejo". In:

GARCIA, Wilton (Org.) Corpo \& Arte: estudos contemporâneos. São Paulo: Nojosa, 2005, pp. 91-104. Republicado em GATTI, José; PENTEADO, Fernando Marques (Org.). Masculinidades: teoria, crítica e artes. São Paulo: Estação das Letras e Cores, 2011, pp. 277-289. 